\title{
A system of shared autonomous vehicles for Chicago: Understanding the effects of geofencing the service
}

\author{
Krishna Murthy Gurumurthy \\ University of Texas at Austin \\ gkmurthy10@utexas.edu
}

\author{
Kara M. Kockelman \\ (corresponding author) \\ University of Texas at Austin \\ kkockelm@mail.utexas.edu
}

\author{
Joshua Auld \\ Argonne National Laboratory \\ jauld@anl.gov
}

\begin{abstract}
With autonomous vehicles (AVs) still in the testing phase, researchers and planners must resort to simulation techniques to explore possible futures regarding shared and automated mobility. An agentbased discrete-event transport simulator, POLARIS, is used in this study to simulate travel in the 20-county Chicago region with a shared AV (SAV) mobility option. Using this framework, the effect of an SAV fleet on system performance when constrained to serve within geofences is studied under four distinct scenarios: service restricted to the city, to the city plus suburban core, to the core plus exurban areas, and to the entire region - along with the choice of dynamic ridesharing (DRS) versus solo travel in an SAV. Results indicate that service areas need a balanced mix of trip generators and attractors, and an SAV fleet's empty VMT (eVMT) can be noticeably reduced through suitable geofencing and DRS. Geofences can also help lower response times, reduce systemwide VMT across all modes, and ensure uniform access to SAVs. DRS is most useful in lowering VMT and \%eVMT that arises from sprawled land development, but with insufficient demand to share rides, savings from the use of geofences is higher. Geofences targeting neighborhoods with high trip density bring about low response times and \%eVMT, but fleet sizes in these regions need to be designed for uniformly low response times throughout a large region, as opposed to maximizing vehicle use in a 24-hour day.
\end{abstract}

\section{Article history:}

Received: November 23, 2020

Accepted: April 4, 2021

Available online: September 8, 2021

\section{$1 \quad$ Motivation}

The world is evolving rapidly, and the era of fully-automated, or autonomous, vehicles (AVs) is around the corner. Waymo, Uber, and others began publicly testing such vehicles in 2017. AVs may be publicly available for use in many locations by year 2035, with many manufacturers (like Ford, Mercedes and GM) and several US states (such as Arizona, California, and Texas) entering the "AV race." AVs are expected to boast several advantages over conventional vehicles, over and above eliminating the burden of driving. Crash rates are likely to drop due to the absence of human error (Fagnant \& Kockelman, 2015), and these vehicles will operate more smoothly, resulting in emission benefits (Lee \& Kockelman,

Copyright 2021 Krishna Murthy Gurumurthy, Joshua Auld \& Kara M. Kockelman

http://dx.doi.org/10.5198/jtlu.2021.1926

ISSN: 1938-7849 | Licensed under the Creative Commons Attribution - Noncommercial License 4.0

The Journal of Transport and Land Use is the official journal of the World Society for Transport and Land Use (WSTLUR) and is published and sponsored by the University of Minnesota Center for Transportation Studies. 
2019; Ross \& Guhathakurta, 2017).

These benefits, however, come at a cost. The state-of-the-art technology will not be affordable in the early stages due to high investment in the development stage and high costs for all the sensors and other equipment required by the system. Acquiring and owning AVs will be expensive and studies reveal a minimum added cost of $\$ 7,500$ to $\$ 10,000$ for automation alone (Fagnant $\&$ Kockelman, 2015; IHS Automotive, 2014), with no definite picture for insurance and maintenance costs. Studies have shown that AV technology is likely to first be taken up by fleet operators (Bansal \& Kockelman, 2017; Quarles et al., 2020), much like current-day transportation network companies (TNCs), who wish to employ shared fleets of $\mathrm{AVs}$ and turn a higher profit by avoiding driver-related costs. Long-term cost estimates for shared AV (SAV) fleets are in the range of $\$ 0.50$ to $\$ 1$ per mile (Becker et al., 2020; Bösch et al., 2018; Fagnant \& Kockelman, 2015; Loeb \& Kockelman, 2019), making them an attractive mode alternative to personally owned vehicles today, which cost about $\$ 0.50-\$ 0.80$ per mile for a gasolinepowered sedan depending on use (American Automobile Association, 2019).

If $\mathrm{SAV}$ s are preferred in the future, it is important that travel demand modelers study the impact SAVs may have on the system to understand and mitigate negative externalities (like congestion, emissions, and inequity) with effective policies. In the recent past, a plethora of studies on single-occupant SAV operation under varying regional settings have warned regions that congestion will worsen through added vehicle-miles traveled (VMT), especially from the non-revenue generating unoccupied miles (empty or eVMT) necessary to pick up travelers (Bischoff \& Maciejewski, 2016; Brownell \& Kornhauser, 2014; Fagnant et al., 2015; Simoni et al., 2019; Spieser et al., 2014). Fleet operational policy, such as allowing multiple travelers to share their rides, called dynamic ride-sharing (DRS), is anticipated to moderate rising congestion from SAV fleets, and, in some cases, even lower congestion by reducing total VMT if large demand for SAVs exists (Alonso-Mora et al., 2017; Fagnant \& Kockelman, 2018; Heilig et al., 2017; Martinez \& Viegas, 2017). However, traveler willingness to share a ride may not be uniform and will depend on user preference (Gurumurthy \& Kockelman, 2020a; Lavieri \& Bhat, 2019; Stoiber et al., 2019), in addition to some spatial and time-of-day effects. Congestion pricing was shown to help observe system benefits even with single-occupant SAVs, where overall traveler welfare improved with these pricing schemes (Kaddoura et al., 2020; Simoni et al., 2019). Pricing trips has also been found to have a moderating effect on rising VMT when combined with DRS when mode shares for SAVs remain low (Gurumurthy et al., 2019). This emphasizes the mixture of policies necessary in order to observe net benefits for all travelers using any mode.

System-wide and fleet-wide policies are crucial to managing rising congestion, and several fleetrelated parameters (such as fleet sizing and response time reliability) are also known to have an effect on realizing the expected policy benefits. Brownell and Kornhauser (2014) analyzed SAVs operating across the entire state of New Jersey, and found a significant reduction in region-wide vehicles (one-third of the region's personal-vehicle fleet size) is needed to serve the same number of trips when SAVs work to feed transit. Unlike Brownell and Kornhauser's approximation of a travel demand model, Spieser et al. (2014) used real-world taxi data for Singapore with a similar replacement ratio, but taxi trips formed a relatively small percentage of all trips. Gurumurthy and Kockelman (2018) used a large cellphone dataset and a detailed network to show that sharing with SAVs may only be viable when trip densities are high, and that VMT is likely to increase (up to 4\%) for high-use scenarios without the introduction of other supplementary policies. Congestion feedback, and, consequently mode choice, is important to see how induced demand will be handled by SAVs. Studies using MATSim (Horni et al., 2016), attempted to fill these gaps by using detailed networks (Bösch et al., 2016; Liu et al., 2017; Loeb \& Kockelman, 2019; Loeb et al., 2018) while also allowing for mode choice and congestion pricing (Gurumurthy et al., 2019; Simoni et al., 2019). While some previous studies with trips being served only by SAVs showed VMT savings with DRS, Gurumurthy et al. (2019) revealed that small mode shares of SAVs 
may negatively impact system VMT. Congestion pricing, as well as fleet sizing, was jointly needed to moderate the rise in system VMT in the Gurumurthy et al. Austin application.

Higher productivity is expected when traveling in an AV, and this is likely to impact a traveler's destination choice. Short-distance trips that were not frequented in a personal vehicle previously may now be made in an SAV, but many MATSim studies do not yet capture this demand shift. Martinez and Viegas (2017) use mode-choice and destination-choice for Lisbon, Portugal with DRS enabled and predict VMT savings of up to $30 \%$, but they do so using aggregated data. Lisbon is only about one-tenth the size of other cities mentioned here, so valuable insights may have been lost. Similarly, Heilig et al. (2017) predict VMT savings of 20\% using SAVs with DRS for Stuttgart, Germany using a macroscopic traffic assignment model, which simplifies link-level congestion. What this means is that there is a need to use a finer-scale simulation tool that incorporates mode-choice, destination-choice, and congestion feedback along with a comprehensive travel dataset and a detailed network to holistically understand SAV fleet impacts.

In this study, an agent-based discrete event transport simulator, called POLARIS (Auld et al., 2016), is used to understand SAV fleet operation in the Greater Chicago region, which contains 20 counties and home to nearly $11 \mathrm{M}$ people. POLARIS is a detailed agent-based travel simulator with relatively lower computation times than MATsim, and can simulate the region's current travel in about 5 to 7 hours (depending on various settings) on a 24-core computer with 128 GB memory. It includes modules for destination choice, timing choice, mode choice, and schedule-based transit simulation, which can be iterated with congestion feedback. This study further contributes by understanding the effect of geofencing the shared service, with and without DRS, for different forecasted SAV demands while focusing on change in system VMT, and empty or unoccupied VMT (eVMT) in an SAV. The remaining sections of the paper are organized as follows: the dataset for the Greater Chicago region is described in detail, followed by a description of POLARIS and its components including the SAV modules used; then, the four scenarios for geofencing the service are described, concluding with the results and discussion.

\section{Greater Chicago dataset}

The dataset for the 20-county Chicago region is based on several statistical models that are fed into a population and travel demand synthesizer to get an accurate representation of trips made in the region. Figure 1 shows the network used here and was obtained from the Chicago Metropolitan Agency for Planning (CMAP), the local metropolitan planning organization. The network consists of about 31,000 links and 19,000 nodes, and around 11 million travelers make about 30 million one-way person-trips in one 24-hr day on this network. All trips that are synthesized are cross-referenced spatially with traffic analysis zones (TAZs). The entire region is comprised of 1,961 TAZs, which are further classified based on land-use and proximity to Chicago's central business district (CBD). Nearly $78 \%$ of person-trips are made by private car, $6 \%$ by transit, $12 \%$ are by walking/biking, and $3 \%$ are by taxis $\&$ TNCs. Travel patterns from the synthetic population have been validated using the CMAP travel survey for the region (Auld et al., 2016), and have undergone recalibration since then. 


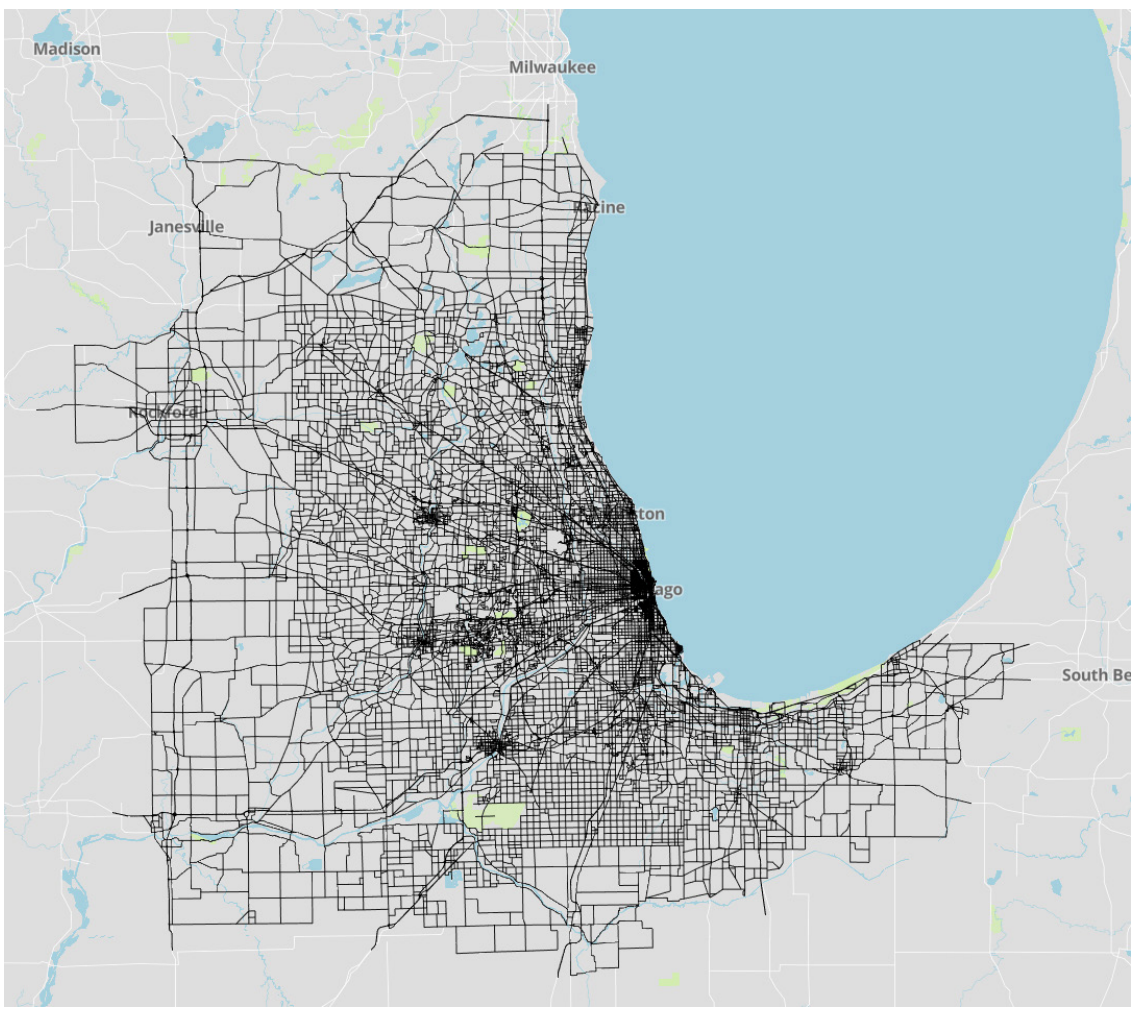

Figure 1. Detailed network of the 20-county Chicago region

\section{$3 \quad$ Modeling in POLARIS}

POLARIS is an agent-based transport simulation tool that uses a discrete-event engine to simulate activities for all travelers. It is comprised of different modules that handle person, vehicle, activity, transit, and logging tasks. A population synthesizer creates a representative set of travelers for the region, and a series of behavioral econometric models create the activities and travel itinerary for each individual. During the simulation, an activity conflict monitor tracks delays in travel. Personal vehicle ownership, vehicle technology, departure time, and mode choice are controlled at the household and person levels. The planning and scheduling of travelers' activities has been adapted from the ADAPTS model (Auld \& Mohammadian, 2009, 2012). Detailed workflow diagrams for POLARIS are presented in Auld et al. (2016). A hybrid dynamic traffic assignment method is used where travelers are able to switch routes based on delays. Routing in POLARIS uses a time-dependent A-star router (Verbas et al., 2018), where resulting route travel times are looped back to activity and trip choices. At the link level, a mesoscopic traffic-flow model provides speed and accuracy in modeling vehicle flow every 6 seconds (de Souza et al., 2019).

\section{$4 \quad$ Shared autonomous vehicles}

SAV operations are adapted from Gurumurthy et al. (2020) and extended to limit the spatial scope of service within a geofence. SAV demand was modeled to closely resemble TNC use, and is impacted by average response times and fares, in addition to user preference for SAV use. SAVs operate on the same 
network as other simulated modes and were able to capture congestion effects. SAVs were matched to trip requests through a central fleet operator such that the location and status of every SAV was available at all times. A zone-based matching structure was used for computational efficiency, as detailed in Gurumurthy et al. (2020). This structure allowed for a pre-defined input to limit the maximum response time, which is assumed to be $30 \mathrm{~min}$ in this study. Requests originating in the periphery of the region may be skipped with a smaller threshold, but by using a 30-min maximum, the response times observed for such trip requests can be visualized and critiqued. All analysis assumes that SAVs operate on the roadway like traditional ridesourced vehicles. SAV vehicles store information about assigned requests, current occupants, and real-time location, which is communicated with the central operator for future request assignments. Detailed trip level information is logged such that SAV tours, consisting of a pickup and dropoff component, or a chain of the same, can be analyzed.

The on-demand service offered by SAVs can be priced by the mile and by the minute along with a base fare, as is widely practiced by TNCs. A base case simulation run here used present-day averages of TNC and taxi fares: a base fare of $\$ 3.30, \$ 1.25$ per mi and $\$ 0.25$ per min. Fares impact the outcome of the mode choice for each person, and SAV demand is likely to be influenced by low-cost fares in the future. Studies have shown that the likely costs for operation are about $50 \$ / \mathrm{mi}$ to $\$ 1 / \mathrm{mi}$ (Becker et al., 2020; Bösch et al., 2018; Fagnant et al., 2015; Loeb \& Kockelman, 2019). To simplify the analyses, a per-mile fare is used such that the average cost of operation is exactly $50 \AA / \mathrm{mi}$.

Travelers requesting rides in the future may also be willing to share rides. DRS is modeled in POLARIS, but with the assumption that all travelers were willing to share rides if using the SAV fleet. Research on traveler willingness to share rides has found that the predominant reason to not share a ride is the extent of delays observed (Bilali et al., 2019; Gurumurthy \& Kockelman, 2020a; Lavieri \& Bhat, 2019). A heuristic is implemented to manage traveler delays. Since the extent of experienced delay cannot be known at the start of a trip, the estimated delays throughout the trip are used to influence choice. The heuristic tracks the delay experienced at several stages of the trip, and stops an SAV from accepting new rides if any occupant experiences an approximate delay greater than a pre-defined input ( 5 min or $5 \%$ of delay). Trip matching is also restricted to travelers traveling in the approximately the same direction (a 10-degree cone such that destinations far away can have a larger leeway in detour), so that experienced delays are not much higher than the threshold used. For a detailed overview of the DRS heuristic used in POLARIS, refer to Gurumurthy and Kockelman (2020b).

\section{Conventional vehicle ownership}

Lower fares for SAVs are expected to attract a large share of users in the future, especially when they do not have access to personal cars, or are, otherwise, unable to drive one. The mode choice model used by POLARIS takes into account mode-specific generalized costs, as well as expected mode travel times, which are good predictors of mode choice, in addition to other estimated household- and person-level parameters. In the case of modeling SAVs, however, it is difficult to estimate a mode choice model with real data, since none exists. Using lower fares alone, as stated earlier, does not produce the expected change in shares, since the data used to estimate the fares were based on present-day TNCs that charge higher fares, and extrapolating a model to a region with no data is not advisable. Some research points to the gradual decline of conventional vehicle ownership, and, consequent adoption of SAVs when personal AVs are still expensive (Lavieri et al., 2017; Menon et al., 2019; Quarles et al., 2019). In this future, households are expected to own fewer conventional vehicles and prefer to make trips by low-cost SAVs. Households located closer to economic hubs, like downtown Chicago, may especially exhibit this behavior. More households in the suburbs may also be willing to let go of one or more vehicles than 
those in exurban areas, thereby increasing the demand for shared modes. Menon et al.'s (2019) ordered probit model was implemented in POLARIS as explained in Gurumurthy et al. (2020). The use of individual, household, land-use and trip data provides a plausible forecast of reduced household vehicle ownership. The resulting increase in SAV reliance in these neighborhoods may necessitate a reliable SAV service. In addition to the model estimated by Menon et al. (2019), and other land-use and accessibility variables, SAV reliability may also influence households to let go of more vehicles. Reverse dependence of SAV fare was also included in the model, to observe a differential travel demand when large low-cost fleets are available on-demand. However, this behavior could not be calibrated, but provides for household vehicle disposal in the direction suggested by Menon et al.'s (2019) model. The SAV mode share is still not expected to dominate with the models used here, as these shares are based only on one possible future of AV use when augmenting current preferences, whereas public opinion is still evolving. Fleet size for both single-occupant and DRS operation was estimated for this future vehicle scenario such that one SAV is available for every 100 residents served in the region.

Past work has shown that increased trip-making density also has a marginal positive impact on fleet operations through better trip matching if travelers are able to pool their rides (Gurumurthy \& Kockelman, 2020b; Yan et al., 2020). Yan et al. (2020) used a small sample for Minneapolis-St Paul, whereas Gurumurthy and Kockelman (2020b) focused on the small region of Bloomington, Illinois, so there is little known on how trip-making density in a sprawling region affects SAV operation. To this end, an alternative scenario with demand served by SAVs is explored. Fleet size was assumed such that one SAV is available for every 10 residents in the region served. Results from this SAV preference scenario will help explore whether geofences are effective when a larger proportion of trips are made using SAVs.

\section{The geofence}

Past studies point toward the rise in VMT and eVMT with the use of SAVs as noted earlier. Research has shown that DRS can mitigate a part of this issue, but the percentage of travelers willing to share their rides in the near future is key, but remains low (Gurumurthy \& Kockelman, 2020a; Krueger et al., 2016; Lavieri \& Bhat, 2019; Stoiber et al., 2019). With the sprawling nature of urban regions in the U.S., trips being made, for example, from a city's CBD to a suburban or exurban home is, on average, longer than the average trip length for city dwellers. SAVs are expected to be beneficial with cost-savings and emission-benefits, but, at the same time, an in-depth analysis of policies that can curb rising VMT needs to be studied. Fagnant et al. (2015) suggest that areas with higher trip densities are better suited for SAV operations since SAVs in these settings lower total VMT in the system. Constraining SAV fleet service within a carefully chosen geofence may provide some congestion mitigation, but the impact of such a policy has not been tested. Many cities and regions in the US currently have some regulation if ridesourcing companies operate within their jurisdiction, but these fleets are mostly unregulated otherwise, and it is hard to know if these services are operating in the periphery. With current ridesourcing levels expected to be low in rural settings, there has been no locus for constraining fleet operation within fixed boundaries. Even if demand rose, regulating a geofence may be a logistical nightmare for networks of all sizes.

With SAVs anticipated to have state-of-the-art GPS technology, tracking and enforcement is likely to require no added effort, making spatial regulation feasible. Travelers will also be able to identify whether an SAV service is available based on their location. This study incorporates a virtual geofence closely resembling the spatial extents of TAZs, an intrinsic component of the POLARIS framework. With a geofence, only trips originating and ending geographically within the enforced fence will be 
served by SAVs. The Chicago region is vast and consists of several suburban cities, and land-use and trip-densities vary drastically from the City of Chicago's CBD to the exurban region. Four scenarios are proposed here with three distinct geofences, and one without a fence for baseline comparison. The geofences are chosen based on either municipal jurisdiction - like the City of Chicago - or the varying land-use based on home density and job density - suburbs and the exurban region. Figure 2 shows the spatial expanse of the geofences stacked, such that an exurban geofence, for example, covers suburban and city limits.

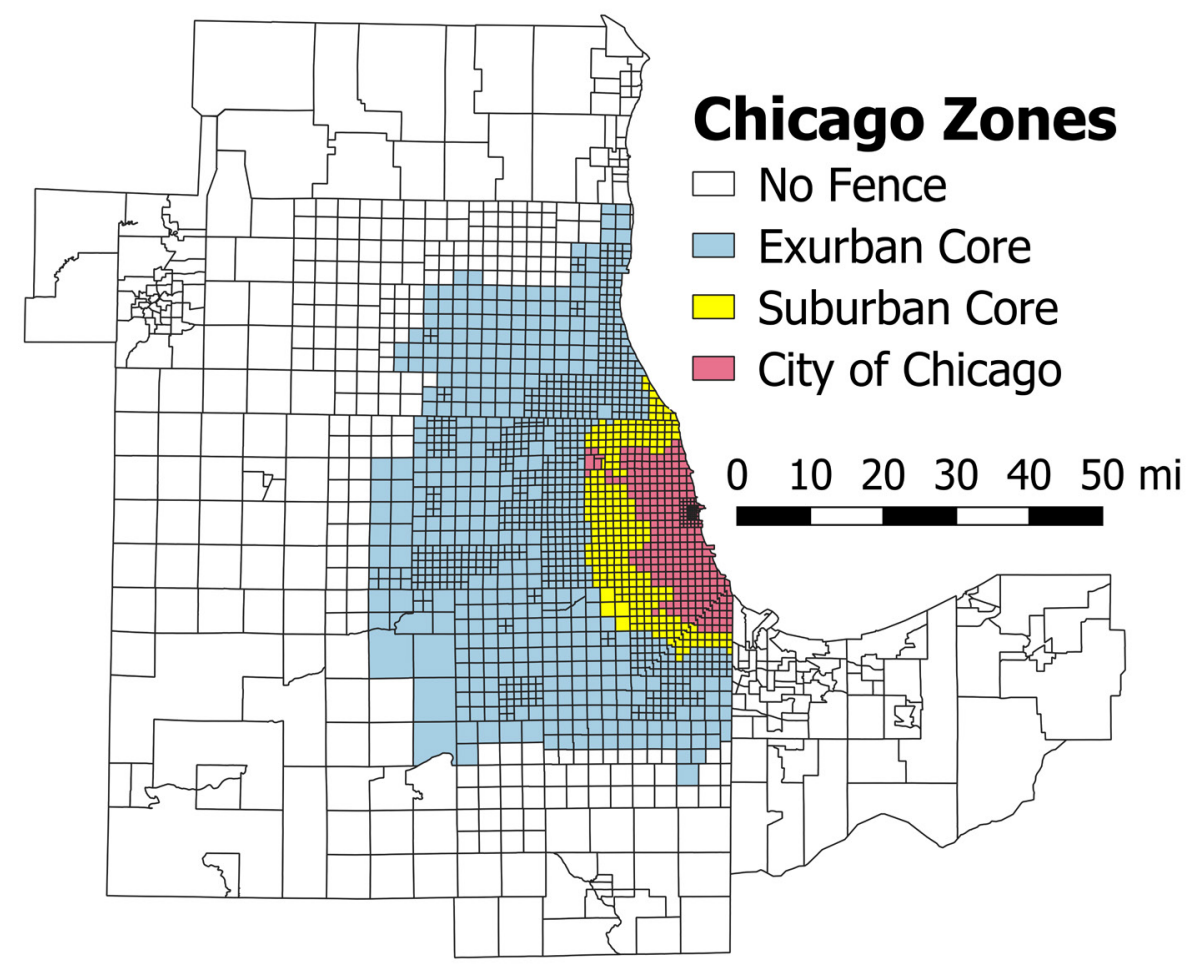

Figure 2. Spatial extent of geofences (stacked) in the Chicago region's TAZs

\section{$7 \quad$ Results}

POLARIS was used to simulate travel for the three geofence scenarios mentioned above to restrict SAV eVMT. The simulation results partially confirmed the initial hypothesis that geofencing trips served by SAVs can decrease eVMT and lower SAV wait times. Although average response times do not decrease by much, the spatial variation of response times becomes more uniform and equitable. However, it was also apparent that the spatial choice of the geofence played a significant role, at least when SAVs formed only a part of the mode share. To understand the characteristic of a geofence that helped lower eVMT, the person-trip density served within the geofenced region was compared with observed eVMT.

Figure 3 shows bar plots of eVMT along with the person-trip density served by SAVs for each scenario discussed. A base case eVMT is also plotted alongside the single-occupant and DRS operation. The base case values stem from a present-day scenario without geofences or low-cost SAVs. Instead, eVMT in this case refers to deadheading trips in a TNC, but it is important to note that a time-varying fleet and decentralized dispatch was not modeled for a true ridesourcing application. For a fair comparison, trips originating and ending within the geofenced region were used to compute the share of deadheading trips. There is some bias here since the comparison uses deadheading trips as the only refer- 
ence, which means that the consequent dropoff trip may have left the geofence. Regardless, the clear fall in person-trip density observed when transitioning from a suburban geofence to an exurban or lack of a geofence corresponds well to a rise in \%eVMT for all SAV scenarios illustrated. This change due to underlying land-use is seen to significantly influence the viability of the geofence. For desirable SAV operation, most trips need to start and end within a dense region. New York is a good example where most trips start and end within the dense island, if trips are made on road. The eVMT with a geofence around the city was about 14\%, but total trip average idle times shown in Table 1 imply the use of an oversized fleet. Empty VMT for the City of Chicago is comparable to that of Austin, Texas (Gurumurthy et al., 2019), as are the two spatial extents. DRS helps lower \%eVMT further, and this decrease is greater when larger areas are served. Sprawling regions may see pickup trips in several distinct directions if serving only one traveler at a time, so the use of DRS has more scope in sprawling regions than in dense regions. However, DRS can moderate rising eVMT only to some extent, beyond which trip-density plays a larger role. SAVs serving trips within the exurban geofence show similar $\% \mathrm{eVMT}$ as the use of no fence. Demand outside of the exurban area may decrease radially outward, partly from the vehicle ownership model pushing suburban households to dispose of more vehicles than exurban households. Compared to the base case with a smaller demand for the ridesourcing fleet, \%eVMT increased when not using a fence. Percent eVMT in the SAV preferred scenario also remained low thanks to increased trip density and DRS that may have helped chain trips even in the periphery of the service area.

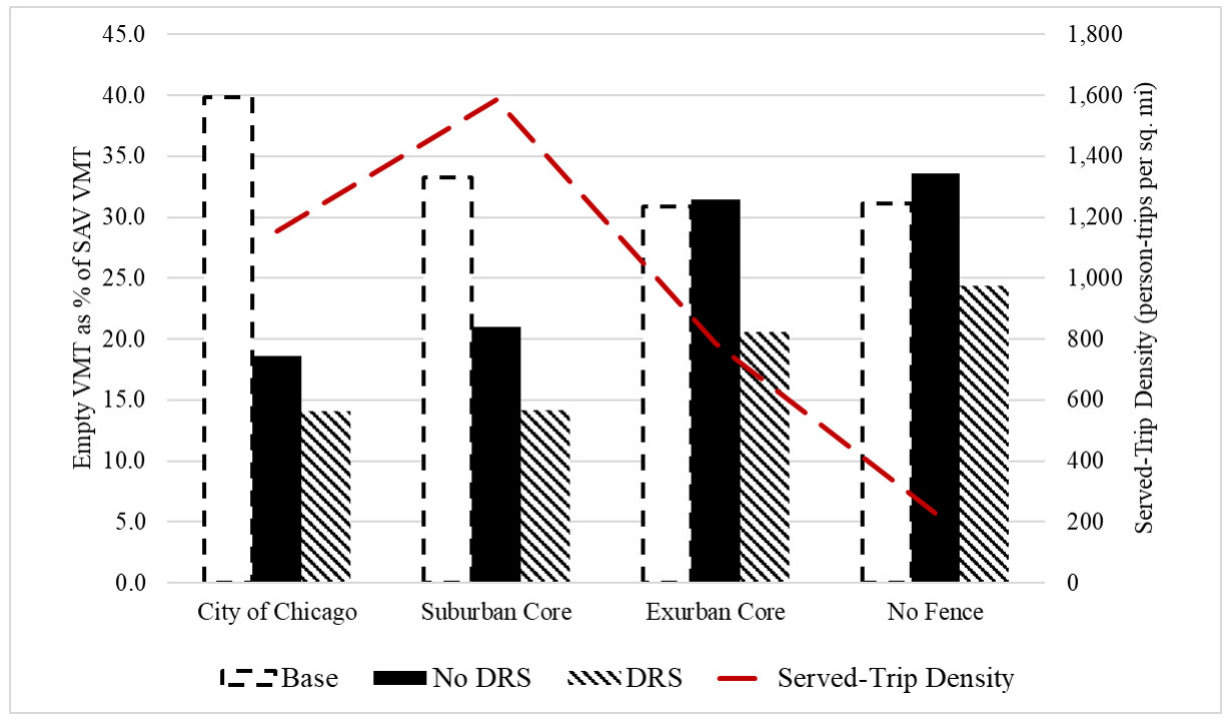

Figure 3. Served-trip density in geofence influencing empty VMT

Table 1 shows the average response time, average person-trips served per SAV per day, \% idle time in a 24-hr day, and the average VMT traveled per SAV in the simulation day. The observed average household vehicle ownership within these geofences from using Menon et al.'s (2019) vehicle disposal model is also reported, and can be compared to the base case average vehicle ownership of 1.63 vehicles per household.

A constant SAV availability assumption based on residents in the region is only a substitute for the ratio of person-trips to SAVs. However, mode choice that is affected by fleet size makes it difficult to maintain a constant ratio across geofences. Without a fence, the average response times were higher compared to any fenced scenario. It is interesting to note that response times remain unaffected by DRS 
when SAVs serve larger spatial extents, with almost 1 min of response time added to the average for the city and suburban geofences. This effect may be seen as DRS being more useful in sprawling regions than densely packed regions. More trips were served, on average, with DRS when including the sprawling regions. This may also be attributed to more travelers being willing to use SAVs than was allowed by the same fleet size without DRS. Low \% idle times for service within the exurban region and without a fence show that the fleet was likely used exhaustively. This can also explain the steep increase in \%eVMT observed. Since average SAV VMT per day is higher than in most studies, it is likely that the demand within the exurban region is considerably more per SAV provided in suburban or city limits. Large AVO when serving a larger region is counter-intuitive from a trip density perspective, since trip density peaked within the suburban geofence, but average trips served is lower than in the exurban region. Turning back to average idle time, the number of SAVs serving the suburban region is likely high for the number of trips made there. Right-sizing the fleet for trips within the suburban region seems to hold key potential based on trips served in the relatively small region.

Figure 4 shows the mode shares across the two sets of scenarios with and without DRS for all trips within the geofences. The shares remain nearly the same irrespective of the use of DRS, with mode splits for SAVs smaller by less than $0.5 \%$. Even with the vehicle ownership model used here, SAVs form a relatively minor share, especially owing to the region's high use of transit modes for commute and intracity trips. Walk and bike modes are also predominant within the dense city limits, and the auto mode enjoys only about $24 \%$ share.

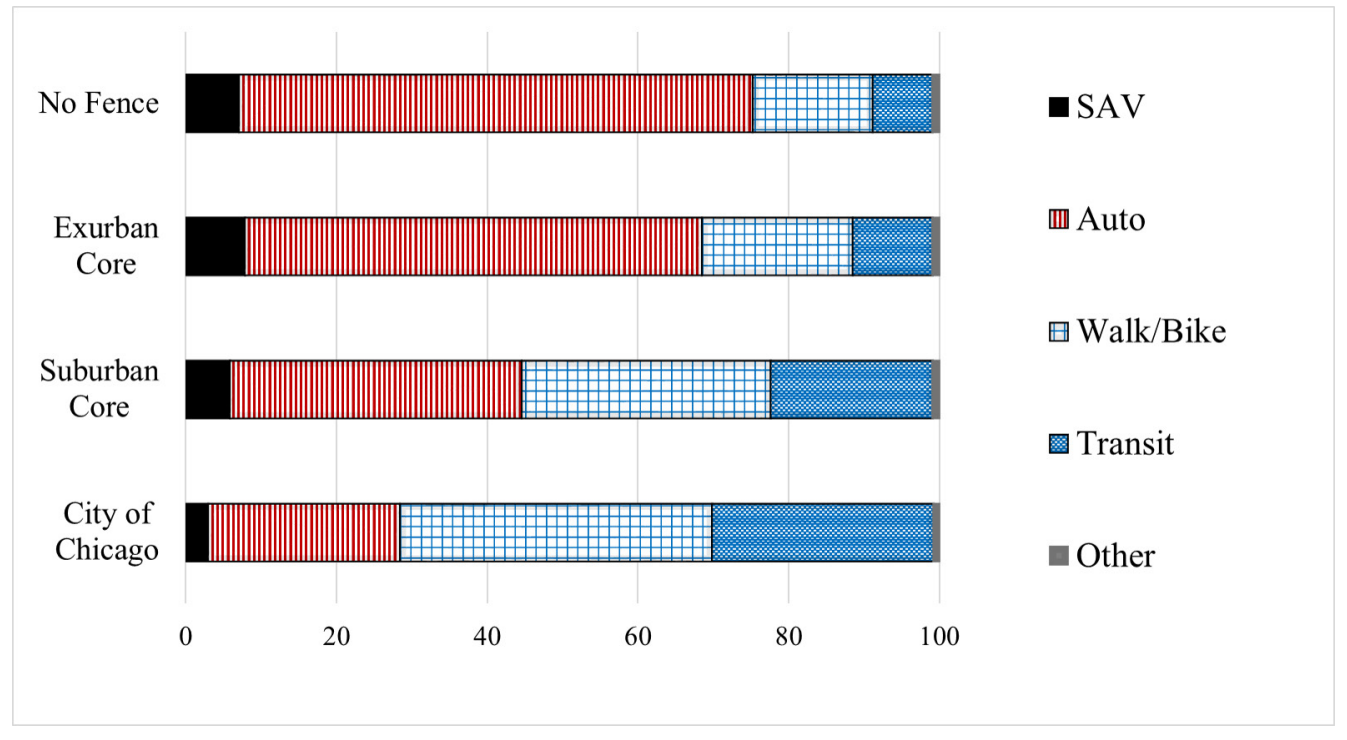

Figure 4. Mode shares within geofences for both non-DRS and DRS scenarios

Table 2 shows similar SAV fleet operation metrics as discussed with the option of mode choice, but for the scenario where all auto trips are served by SAVs. An additional metric for percentage of trips served is included here, since travelers within the geofences were assumed to have no alternative mode of transport in order to quantify the service for all trips served. The served-trip density for SAVs in these scenarios is about an order of magnitude higher than the previous set of scenarios, but many metrics are largely similar. Increasing trip density within the geofences considerably improved trip shareability, but a larger fleet was needed to serve more than $95 \%$ of the demand in each of these scenarios since alternate modes were assumed to not be available within the geofences. If minimum demand served was 
set at about $85 \%$, more trips may have been bunched together since average empty VMT would drop from avoiding distant pickup trips. The SAV fleet serving the exurban geofence was able to serve, on average, 22.0 person-trips per SAV per day. Comparable values were realized for all fences from the assumption of a fixed fleet. Higher demand densities should allow smaller fleets to serve trips, albeit with some loss in percent demand served. As demand for SAVs increases in the future, it may be prudent for the Chicago region to expand the geofence to the exurban region, assuming that a suburban geofence was used initially, and that demand increased. Allowing SAVs to operate with central dispatch across the 20-county region may add unnecessary eVMT and require a large fleet that would cost more than the benefit it may bring. An interesting point to note is the trend of distance-weighted and trip-weighted AVO values. With mode choice, and less than $5 \%$ of trips served by SAVs, the larger regions opened up more opportunities for shared trips. However, beyond a threshold of mode share for a region, the trip density becomes the driving factor for shareability and an avenue for the most system benefits when relying on a fleet, with some added VMT (about $2 \%$ without a fence).

Figure 5 shows the change in system VMT for each of the geofences, with and without DRS, and when auto trips are made by SAVs. Large fleets of SAVs serving large demands are expected to add some VMT, even though \%eVMT remains lower than low SAV demand scenarios. The use of DRS is not seen to have a considerable effect on lowering VMT by itself when demand remains low with the smaller geofences like the City of Chicago, as opposed to the exurban core. Allowing DRS saves more VMT when there's no fence used. When all personal auto demand is served only using SAVs, there is an increase in system VMT by up to $2 \%$. Transit is widely used within the City of Chicago and several commuter lines run radially in the region. In an alternate scenario not shown in the figure, shifting trips from transit to SAVs added congestion irrespective of any fence used. Replacing transit with SAVs in high trip-density areas like within the City of Chicago is expected to maintain demand comparable to present-day mode operations, but the benefit of a supplementing transit system is critical to lower congestion as seen in the figure.

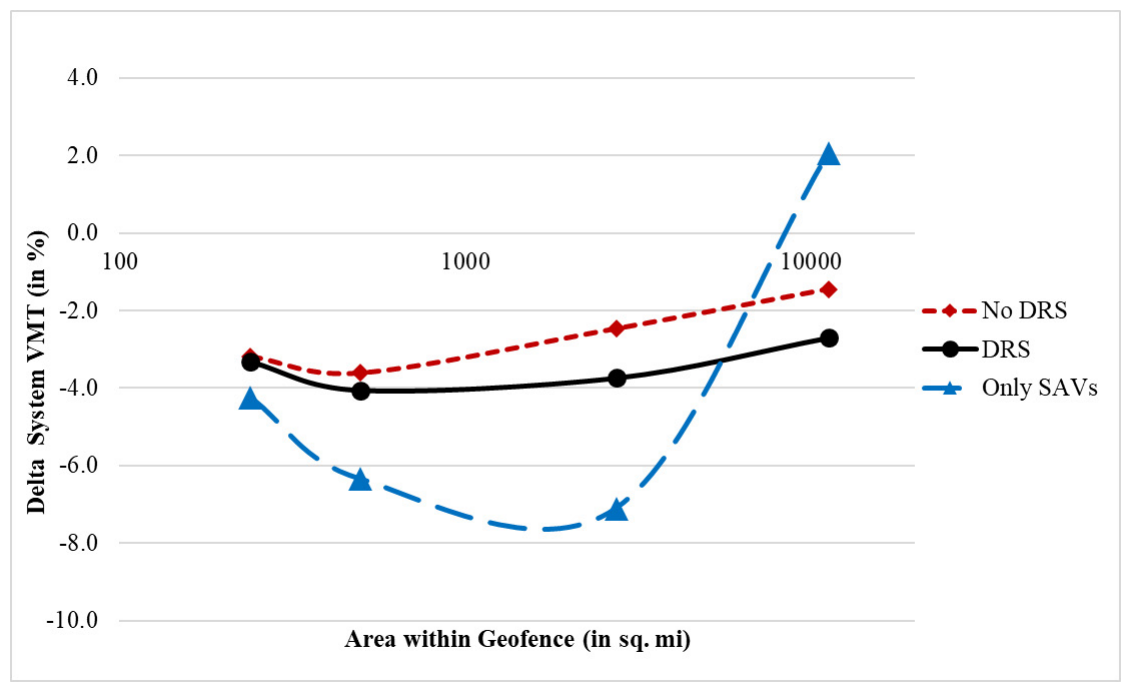

Figure 5. Change in system VMT observed with geofences and DRS Note: Fences shown on log axis based on area within fence 
Table 1. Fleet metrics for 1 SAV for every 100 residents with and without DRS

\begin{tabular}{|c|c|c|c|c|c|c|c|c|c|c|}
\hline $\begin{array}{l}\mathrm{D} \\
\mathrm{R} \\
\mathrm{S} \\
?\end{array}$ & $\begin{array}{l}\text { Avg. HH } \\
\text { Vehicles }\end{array}$ & $\begin{array}{l}\text { Geofence } \\
\text { Scenarios }\end{array}$ & $\begin{array}{l}\text { Area (in } \\
\text { sq. mi) }\end{array}$ & $\begin{array}{c}\text { Avg. } \\
\text { Response } \\
\text { Time (in } \\
\text { min) }\end{array}$ & $\begin{array}{c}\text { Avg. } \\
\text { Person- } \\
\text { Trips per } \\
\text { SAV per } \\
\text { day }\end{array}$ & $\begin{array}{l}\text { Avg. } \% \\
\text { Idle Time } \\
\text { per SAV } \\
\text { per Day }\end{array}$ & $\begin{array}{c}\text { Distance } \\
\text { Weighted } \\
\text { AVO } \\
\text { (with 1+ } \\
\text { passen- } \\
\text { gers) }\end{array}$ & $\begin{array}{c}\text { Trip } \\
\text { Weighted } \\
\text { AVO } \\
\text { (with 1+ } \\
\text { passen- } \\
\text { gers) }\end{array}$ & $\begin{array}{l}\text { Avg. SAV } \\
\text { VMT per } \\
\text { Day (in } \\
\text { mi per } \\
\text { SAV per } \\
\text { day }\end{array}$ & $\begin{array}{c}\text { Served } \\
\text { Trip } \\
\text { Density } \\
\text { (in scaled } \\
\text { person- } \\
\text { trips per } \\
\text { sq. mi) }\end{array}$ \\
\hline \multirow{4}{*}{$\mathrm{N}$} & 0.51 & $\begin{array}{c}\text { City of } \\
\text { Chicago }\end{array}$ & 239 & $4.8 \mathrm{~min}$ & 10.9 & $82.3 \%$ & \multirow{4}{*}{\multicolumn{2}{|c|}{1.00}} & 113.1 & 1154.6 \\
\hline & 0.66 & $\begin{array}{c}\text { Suburban } \\
\text { Core }\end{array}$ & 496 & 6.0 & 20.9 & 62.7 & & & 254.0 & 1585.1 \\
\hline & 1.00 & $\begin{array}{c}\text { Exurban } \\
\text { Core }\end{array}$ & 2730 & 9.8 & 28.2 & 41.4 & & & 487.5 & 787.0 \\
\hline & 1.15 & No Fence & 11246 & 11.5 & 25.8 & 41.4 & & & 517.6 & 229.3 \\
\hline \multirow{4}{*}{ Y } & 0.51 & $\begin{array}{l}\text { City of } \\
\text { Chicago }\end{array}$ & 239 & 5.6 & 11.8 & 83.5 & 1.23 & 1.30 & 103.2 & 1144.1 \\
\hline & 0.66 & $\begin{array}{c}\text { Suburban } \\
\text { Core }\end{array}$ & 496 & 6.4 & 21.8 & 67.8 & 1.29 & 1.39 & 238.3 & 1656.4 \\
\hline & 1.00 & $\begin{array}{c}\text { Exurban } \\
\text { Core }\end{array}$ & 2730 & 9.7 & 32.6 & 41.6 & 1.36 & 1.54 & 496.8 & 909.2 \\
\hline & 1.15 & No Fence & 11246 & 11.6 & 29.1 & 41.5 & 1.36 & 1.59 & 527.2 & 259.5 \\
\hline
\end{tabular}

Table 2. Fleet metrics for an SAV-only scenario operating 1 SAV for every 10 residents

\begin{tabular}{|c|c|c|c|c|c|c|c|c|c|c|c|}
\hline $\begin{array}{l}\text { Geofence } \\
\text { Scenarios }\end{array}$ & $\begin{array}{l}\text { Area (in } \\
\text { sq. mi) }\end{array}$ & $\begin{array}{l}\text { Avg. } \\
\text { Trip } \\
\text { Length } \\
\text { (in mi) }\end{array}$ & $\begin{array}{l}\text { Avg. Re- } \\
\text { sponse } \\
\text { Time } \\
\text { (in min) }\end{array}$ & $\begin{array}{l}\text { Trips } \\
\text { Met }\end{array}$ & $\begin{array}{c}\text { Avg. } \\
\text { Person- } \\
\text { Trips per } \\
\text { SAV per } \\
\text { day }\end{array}$ & $\begin{array}{c}\text { Avg. } \\
\text { \% Idle } \\
\text { Time per } \\
\text { SAV per } \\
\text { Day }\end{array}$ & $\begin{array}{c}\% \\
\text { eVMT }\end{array}$ & $\begin{array}{c}\text { Distance } \\
\text { Weight- } \\
\text { ed AVO } \\
\text { (with 1+ } \\
\text { passen- } \\
\text { gers) }\end{array}$ & $\begin{array}{c}\text { Trip } \\
\text { Weight- } \\
\text { ed AVO } \\
\text { (with 1+ } \\
\text { passen- } \\
\text { gers) }\end{array}$ & $\begin{array}{c}\text { Avg. SAV } \\
\text { VMT } \\
\text { per Day }\end{array}$ & $\begin{array}{l}\text { Served } \\
\text { Trip } \\
\text { Den- } \\
\text { sity (in } \\
\text { scaled } \\
\text { person- } \\
\text { trips per } \\
\text { sq. mi) }\end{array}$ \\
\hline $\begin{array}{l}\text { City of } \\
\text { Chicago }\end{array}$ & 239 & 5.2 & $4.4 \mathrm{~min}$ & $94.9 \%$ & 12.4 & $88.2 \%$ & $13.5 \%$ & 1.48 & 1.68 & $\begin{array}{c}146.1 \\
\text { mi/SAV/ } \\
\text { day }\end{array}$ & 11518.3 \\
\hline $\begin{array}{c}\text { Suburban } \\
\text { Core }\end{array}$ & 496 & 5.9 & 4.8 & 97.4 & 15.9 & 83.1 & 12.6 & 1.46 & 1.67 & 233.8 & 10705.5 \\
\hline $\begin{array}{c}\text { Exurban } \\
\text { Core }\end{array}$ & 2730 & 7.9 & 6.0 & 97.9 & 22.0 & 71.4 & 16.1 & 1.35 & 1.56 & 485.1 & 5630.0 \\
\hline No Fence & 11246 & 9.7 & 8.2 & 93.1 & 22.4 & 63.8 & 21.2 & 1.31 & 1.54 & 646.9 & 1995.4 \\
\hline
\end{tabular}

Geofences were also found to be useful in providing equitable access to SAVs in large regions. Figure 6 shows response times by TAZ, comparing the service without a fence and that applied at the city and exurban limits. Although average response times reported in Table 1 and Table 2 were low, the average TAZ response times show the inequity in access without a fence. TAZs in the periphery of the region experience greater than 20 min response times. This is starkly different than the uniform response times observed by Yan et al. (2020) in Minneapolis-St. Paul. In a practical application, TAZs with aver- 
age response times greater than $15 \mathrm{~min}$, for example, may not even see equal access to SAVs. A geofence around the exurban core considerably improves response times throughout, lowering it by $5 \mathrm{~min}$ across TAZs. The response times across the city TAZs are almost all less than $5 \mathrm{~min}$. This equitable spread in response times is useful but seems to be achieved with a fleet oversupply. If SAVs are meant to help relieve driving burdens, it may be prudent to require oversizing the fleet for equity concerns, even if it means higher \% idle times, and lower person-trips served by the average SAV per day.

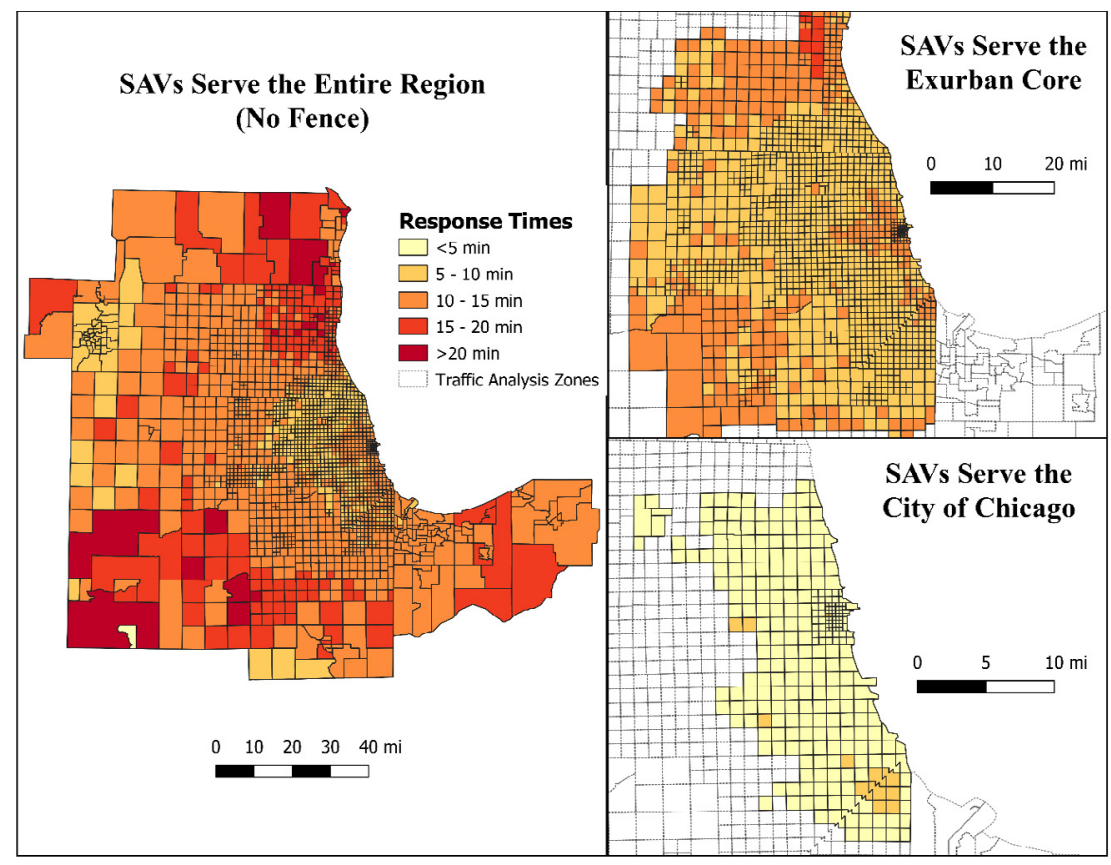

Figure 6. Comparing response times by TAZ between no-fence service and two geofence levels without DRS at the city and exurban limits

\section{Conclusions}

Shared mobility is on the horizon and policy must be developed to tackle initial and future large-scale adoption of SAVs. Regions with urban sprawl, like Chicago, are expected to have high percentages of eVMT arising from longer-than-average trip distances when servicing the exurban areas. In this study, the use of geofences in curbing high anticipated eVMT and VMT is explored. Percent eVMT followed the ratio of residents to jobs in the region served, meaning that balanced generators and attractors in dense regions is ideal if the sole goal is \%eVMT. Fleet size is important to take advantage of high trip densities within a geofence, but fleet size decisions directly impact equity concerns. Fleets must be large enough to provide equitable access spatially, and small enough such that SAVs are used exhaustively in a day (low \% idle time) to warrant the high capital costs of an SAV fleet.

The use of DRS in addition to geofences revealed that DRS alone may not provide large VMT savings. The use of geofences provides larger savings in VMT and this is compounded with higher SAV demand. If regions, like Chicago, are able to shift demands within the suburban extent to SAVs and transit and non-motorized modes, then region-wide VMT savings are realized. Allowing car reliance in rural areas may be acceptable, especially knowing that those roadways are typically not congested. With mode choice available, DRS benefits are more pronounced when serving a larger expanse, as there is more scope for trip bundling with increase in trip demand for SAVs. DRS within city-wide geofences 
showed relatively small changes in total VMT and \%eVMT. When all personal auto trips are served by SAVs, the benefit of a working and heavily-used transit system in Chicago is underscored. SAVs only add about $2 \%$ more VMT without a fence, but savings are expected with fences. Shifting travelers away from transit and to SAVs is detrimental to congestion.

Using geofences also addressed equity of SAV access since it lowers average trip lengths served. The model did use a high threshold for response time to critique the realized response times. Critical demand across the extremities of the region simulated are unlikely to use SAVs due to poor access. The geofences enforced in this study were centered around the City of Chicago. With large regions like this having many smaller CBDs, other geofences can be envisioned around smaller towns. This will not only curb $\%$ eVMT and added VMT, but will also ensure equitable access to most activities less than about $10 \mathrm{~min}$ or $10 \mathrm{mi}$ away. Transit lines or 8-seat automated buses (aBuses) may be able to provide economical access to longer trips without adding considerable congestion on the highway infrastructure.

This study provides an important policy tool in testing travel patterns in large regions with recommendations for use of geofences and a behavioral model informing future SAV demand, but it is also important to keep in mind the limitations that arise from some assumptions made here. Constant SAV availability based on residents limits scope of comparison. Other metrics can be used as a proxy to see how much better the SAV service may have been, but it is difficult to produce a perfect comparison between each geofence scenario. The eVMT resulting from the lack of central operation is likely to be higher and needs to be studied to compare how much better regions can do compared to TNC-related congestion added to streets in several regions. Finally, studies need to evaluate how SAV repositioning in conjunction with the use of geofences can benefit the system.

\section{Acknowledgements}

This report and the work described were sponsored by the U.S. Department of Energy Vehicle Technologies Office under the Systems and Modeling for Accelerated Research in Transportation Mobility Laboratory Consortium, an initiative of the Energy Efficient Mobility Systems Program. David Anderson, a Department of Energy Office of Energy Efficiency and Renewable Energy manager, played an important role in establishing the project concept, advancing implementation, and providing ongoing guidance. The authors would also like to thank Felipe Augusto de Souza for his help with code development and testing, and Maizy (Jade) Jeong for language edits and helping manage submission. 


\section{References}

Alonso-Mora, J., Samaranayake, S., Wallar, A., Frazzoli, E., \& Rus, D. (2017). On-demand high-capacity ride-sharing via dynamic trip-vehicle assignment. Proceedings of the National Academy of Sciences, 114, 462-467. https://doi.org/10.1073/pnas.1611675114

American Automobile Association. (2019). Your driving costs: How much are you really paying to drive? Heathrow, FL: American Automobile Association.

Auld, J., Hope, M., Ley, H., Sokolov, V., Xu, B., \& Zhang, K. (2016). POLARIS: Agent-based modeling framework development and implementation for integrated travel demand and network and operations simulations. Transportation Research Part C: Emerging Technologies, 64, 101-116. https:// doi.org/10.1016/j.trc.2015.07.017

Auld, J., \& Mohammadian, A. (2012). Activity planning processes in the agent-based dynamic activity planning and travel scheduling (ADAPTS) model. Transportation Research Part A: Policy and Practice, 46, 1386-1403. https://doi.org/10.1016/j.tra.2012.05.017

Auld, J., \& Mohammadian, A. (2009). Framework for the development of the agent-based dynamic activity planning and travel scheduling (ADAPTS) model. Transportation Letters 1, 245-255. https:// doi.org/10.3328/TL.2009.01.03.245-255

Bansal, P., \& Kockelman, K. M. (2017). Forecasting Americans' long-term adoption of connected and autonomous vehicle technologies. Transportation Research Part A: Policy Practice, 95, 49-63. https:// doi.org/10.1016/j.tra.2016.10.013

Becker, H., Becker, F., Abe, R., Bekhor, S., Belgiawan, P. F., Compostella, J., ... \& Axhausen, K. W. (2020). Impact of vehicle automation and electric propulsion on production costs for mobility services worldwide. Transportation Research Part A: Policy and Practice, 138, 105-126. https://doi. org/10.1016/j.tra.2020.04.021

Bilali, A., Dandl, F., Fastenrath, U., \& Bogenberger, K. (2019). Impact of service quality factors on ride sharing in urban areas. Paper presented at the 2019 6th International Conference on Models and Technologies for Intelligent Transportation Systems (MT-ITS), Kraków, Poland. https://doi. org/10.1109/MTITS.2019.8883364

Bischoff, J., \& Maciejewski, M. (2016). Simulation of city-wide replacement of private cars with autonomous taxis in Berlin. Procedia Computer Science, 83, 237-244. https://doi.org/10.1016/j. procs.2016.04.121

Bösch, P. M., Becker, F., Becker, H., \& Axhausen, K. W. (2018). Cost-based analysis of autonomous mobility services. Transportation Policy, 64, 76-91. https://doi.org/10.1016/j.tranpol.2017.09.005

Bösch, P. M., Ciari, F., \& Axhausen, K. W. (2016). Autonomous vehicle fleet sizes required to serve different levels of demand. Transportation Research Record, 2542, 111-119. https://doi.org/10.3141/254213

Brownell, C., \& Kornhauser, A. (2014). A driverless alternative: Fleet size and cost requirements for a statewide autonomous taxi network in New Jersey. Transportation Research Record, 2416, 73-81. https://doi.org/10.3141/2416-09

de Souza, F., Verbas, O., \& Auld, J. (2019). Mesoscopic traffic flow model for agent-based simulation. Procedia Computer Science, 151, 858-863. https://doi.org/10.1016/j.procs.2019.04.118

Fagnant, D. J., \& Kockelman, K. (2015). Preparing a nation for autonomous vehicles: Opportunities, barriers and policy recommendations. Transportation Research Part A: Policy and Practice, 77, 167-181. https://doi.org/10.1016/j.tra.2015.04.003

Fagnant, D. J., \& Kockelman, K. M. (2018). Dynamic ride-sharing and fleet sizing for a system of shared autonomous vehicles in Austin, Texas. Transportation, 45, 143-158. https://doi.org/10.1007/ s11116-016-9729-z 
Fagnant, D. J., Kockelman, K. M., \& Bansal, P. (2015). Operations of shared autonomous vehicle fleet for Austin, Texas, market. Transportaion Research Record, 2536, 98-106. https://doi.org/10.3141/253612

Gurumurthy, K. M., de Souza, F., Enam, A., \& Auld, J. (2020). Integrating supply and demand perspectives for a large-scale simulation of shared autonomous vehicles. Transportation Research Record, 2674, 181-192. https://doi.org/10.1177/0361198120921157

Gurumurthy, K. M., \& Kockelman, K. M. (2020a). Modeling Americans' autonomous vehicle preferences: A focus on dynamic ride-sharing, privacy and long-distance mode choices. Technological Forecasting and Social Change, 150, 119792. https://doi.org/10.1016/j.techfore.2019.119792

Gurumurthy, K. M., \& Kockelman, K. M. (2020b). Dynamic ride-sharing impacts of greater trip demand and aggregation at stops. Under review for publication in Transportation Research Part A's special issue The Curb Lane.

Gurumurthy, K. M., \& Kockelman, K. M. (2018). Analyzing the dynamic ride-sharing potential for shared autonomous vehicle fleets using cellphone data from Orlando, Florida. Computers, Environment and Urban Systems, 71, 177-185. https://doi.org/10.1016/j.compenvurbsys.2018.05.008

Gurumurthy, K. M., Kockelman, K. M., \& Simoni, M .D. (2019). Benefits and costs of ride-sharing in shared automated vehicles across Austin, Texas: Opportunities for congestion pricing. Transportation Research Record, 2673, 548-556. https://doi.org/10.1177/0361198119850785

Heilig, M., Hilgert, T., Mallig, N., Kagerbauer, M., \& Vortisch, P. (2017). Potentials of autonomous vehicles in a changing private transportation system - a case study in the Stuttgart region. Transporation Research Procedia, 26, 13-21. https://doi.org/10.1016/j.trpro.2017.07.004

Horni, A., Nagel, K., Axhausen, K. W. (Eds.). (2016). The multi-agent transport simulation MATSim. London: Ubiquity Press. Retrieved from https://doi.org/10.5334/baw

Juliussen, E., \& Carlson, J. (2014). Emerging technologies: Autonomous cars-Not if, but when.

IHS Automotive. http://press.ihs.com/press-release/automotive/self-driving-cars-movingindustrys-drivers-seat.

Kaddoura, I., Bischoff, J., \& Nagel, K. (2020). Towards welfare optimal operation of innovative mobility concepts: External cost pricing in a world of shared autonomous vehicles. Transportation Research Part A: Policy and Practice, 136, 48-63. https://doi.org/10.1016/j.tra.2020.03.032

Krueger, R., Rashidi, T. H., \& Rose, J. M. (2016). Preferences for shared autonomous vehicles. Transportation Research Part C: Emerging Technologies, 69, 343-355. https://doi.org/10.1016/j. trc.2016.06.015

Lavieri, P. S., \& Bhat, C. R. (2019). Modeling individuals' willingness to share trips with strangers in an autonomous vehicle future. Transportation Research Part A: Policy and Practice, 124, 242-261. https://doi.org/10.1016/j.tra.2019.03.009

Lavieri, P. S., Garikapati, V. M., Bhat, C. R., Pendyala, R. M., Astroza, S., \& Dias, F. F. (2017). Modeling individual preferences for ownership and sharing of autonomous vehicle technologies. Transportation Research Record, 2665, 1-10. https://doi.org/10.3141/2665-01

Lee, J., \& Kockelman, K. M. (2019). Energy and emissions implications of self-driving vehicles. Paper presented at the 98th Annual Meeting of the Transportation Research Board, Washington, DC.

Liu, J., Kockelman, K. M., Bösch, P. M., \& Ciari, F. (2017). Tracking a system of shared autonomous vehicles across the Austin, Texas, network using agent-based simulation. Transportation, 44, $1261-$ 1278. https://doi.org/10.1007/s11116-017-9811-1

Loeb, B., \& Kockelman, K.M. (2019). Fleet performance and cost evaluation of a shared autonomous electric vehicle (SAEV) fleet: A case study for Austin, Texas. Transportation Research Part A: Policy and Practice, 121, 374-385. https://doi.org/10.1016/j.tra.2019.01.025 
Loeb, B., Kockelman, K. M., \& Liu, J. (2018). Shared autonomous electric vehicle (SAEV) operations across the Austin, Texas, network with charging infrastructure decisions. Transportation Research Part C: Emerging Technologies, 89, 222-233. https://doi.org/10.1016/j.trc.2018.01.019

Martinez, L. M., \& Viegas, J. M. (2017). Assessing the impacts of deploying a shared self-driving urban mobility system: An agent-based model applied to the city of Lisbon, Portugal. International Journal of Transportation, Science and Technology, 6, 13-27. https://doi.org/10.1016/j.ijtst.2017.05.005

Menon, N., Barbour, N., Zhang, Y., Pinjari, A. R., \& Mannering, F. (2019). Shared autonomous vehicles and their potential impacts on household vehicle ownership: An exploratory empirical assessment. International Journal of Sustainable Transportation, 13, 111-122. https://doi.org/10.1080/15 568318.2018.1443178

Quarles, N. T., Kockelman, K. M., \& Lee, J. (2020). Americans' plans for acquiring and using electric, shared and self-driving vehicles. Paper presented at the 99th Annual Meeting of the Transportation Research Board, Washington, DC.

Quarles, N. T., Kockelman, K. M., \& Lee, J. (2019). America's fleet evolution in an automated future. Forthcoming in Research in Transportation Economics.

Ross, C., \& Guhathakurta, S. (2017). Autonomous vehicles and energy impacts: A scenario analysis. Energy Procedia, 143, 47-52. https://doi.org/10.1016/j.egypro.2017.12.646

Simoni, M. D., Kockelman, K. M., Gurumurthy, K. M., \& Bischoff, J. (2019). Congestion pricing in a world of self-driving vehicles: An analysis of different strategies in alternative future scenarios. Transportation Research Part C: Emerging Technologies, 98, 167-185. https://doi.org/10.1016/j. trc.2018.11.002

Spieser, K., Treleaven, K., Zhang, R., Frazzoli, E., Morton, D., \& Pavone, M. (2014). Toward a systematic approach to the design and evaluation of automated mobility-on-demand systems: A case study in Singapore. In G. Meyer \& S. Beiker (Eds.), Road vehicle automation, lecture notes in mobility (pp. 229-245). New York: Springer International Publishing. https://doi.org/10.1007/978-3-31905990-7_20

Stoiber, T., Schubert, I., Hoerler, R., \& Burger, P. (2019). Will consumers prefer shared and pooled-use autonomous vehicles? A stated choice experiment with Swiss households. Transportation Research Part D: Transport and Environment, 17, 265-285. https://doi.org/10.1016/j.trd.2018.12.019

Verbas, Ö., Auld, J., Ley, H., Weimer, R., \& Driscoll, S. (2018). Time-dependent intermodal A* algorithm: Methodology and implementation on a large-scale network. Transportation Research Record, 2672, 219-230. https://doi.org/10.1177/0361198118796402

Yan, H., Kockelman, K. M., \& Gurumurthy, K. M. (2020). Shared autonomous vehicle fleet performance: Impacts of parking limitations and trip densities. Transportation Research Part D 89, 102577. 